\title{
Correction to: Thermodynamics of protein folding: methodology, data analysis and interpretation of data
}

\author{
Seyedeh Akram Shirdel ${ }^{1} \cdot$ Khosrow Khalifeh $^{2}$ (D)
}

Published online: 21 December 2021

(c) European Biophysical Societies' Association 2021

\section{Correction to:}

\section{European Biophysics Journal (2019) 48:305-316} https://doi.org/10.1007/s00249-019-01362-7

The original publication contains two typo errors that should be amended.

Equation (10) is provided as the following format:

$$
\mathbf{K}_{\mathrm{obs}}=\frac{\mathrm{S}_{\mathrm{up}}-\mathrm{S}_{\mathrm{down}}}{\mathrm{S}_{\mathrm{obs}}-\mathrm{S}_{\mathrm{down}}}
$$

It should be changed into the following format:

$$
\mathbf{K}_{\mathrm{obs}}=\frac{\mathrm{S}_{\mathrm{up}}-\mathrm{S}_{\mathrm{obs}}}{\mathrm{S}_{\mathrm{obs}}-\mathrm{S}_{\mathrm{down}}}
$$

The original article can be found online at https://doi.org/10.1007/ s00249-019-01362-7.

Khosrow Khalifeh

Khalifeh@znu.ac.ir

1 Department of Biochemistry, Faculty of Biological Sciences, Tarbiat Modares University, Tehran, Iran

2 Department of Biology, Faculty of Sciences, University of Zanjan, University Blvd, Zanjan 45371-38791, Iran
In page 308 (second column, last line), the word "mutants" should be changed to "mutant".

Publisher's Note Springer Nature remains neutral with regard to jurisdictional claims in published maps and institutional affiliations. 